\title{
The Association Between Short-Term Air Pollution Exposure and Post-Adolescent Acne: The Evidence from a Time Series Analysis in Xi'an, China
}

\author{
Xiang Li, ${ }^{1,2, *}$ Shu-Jie An, ${ }^{3, *}$ \\ Xiao-Ling Liu, ${ }^{1} *$ Ai-Ling Ji, ${ }^{4}$ \\ Yi Cao, ${ }^{5}$ Ying Xiang, ' \\ Xiang-Yu Ma,' Qin Hu, ' \\ Zhi-Quan Yuan,' Ya-Fei Li, \\ Yuan-Gang Lu, (D) ${ }^{2}$ Tong-Jian Cai ${ }^{\prime}$ \\ 'Department of Epidemiology, College of \\ Preventive Medicine, Army Medical \\ University (Third Military Medical \\ University), Chongqing, People's Republic \\ of China; ${ }^{2}$ Department of Plastic \& \\ Cosmetic Surgery, Daping Hospital, Army \\ Medical University (Third Military \\ Medical University), Chongqing, People's \\ Republic of China; ${ }^{3}$ Medical Department, \\ Xijing Hospital, Air Force Medical \\ University (Fourth Military Medical \\ University), Xi'an, People's Republic of \\ China; ${ }^{4}$ Department of Preventive \\ Medicine \& Chongqing Engineering \\ Research Center of Pharmaceutical \\ Sciences, Chongqing Medical and \\ Pharmaceutical College, Chongqing, \\ People's Republic of China; \\ ${ }^{5}$ Department of Health Economics \\ Management, Xijing Hospital, Air Force \\ Medical University (Fourth Military \\ Medical University), Xi'an, People's \\ Republic of China
}

*These authors contributed equally to this work

Correspondence: Yuan-Gang Lu Department of Plastic \& Cosmetic Surgery, Daping Hospital, Army Medical University, 10 Changjiang Branch Road, Daping, Chongqing, 400042, People's

Republic of China

Tel +86-23-68757597

Fax +86-23-68757596

Email skin5I5@I63.com

Tong-Jian Cai

Email ctjcsl@fmmu.edu.cn
Background: Post-adolescent acne is a common skin disease faced by adults. However, whether air pollution (AP) serves as a risk factor for post-adolescent acne remains elusive. Aim: To determine the relationship between short-term AP exposure (within 7 days) and outpatient visits for post-adolescent acne.

Methods: Daily outpatient visit data for post-adolescent acne and routinely AP data between 2010 and 2013 were collected from Xi'an, China. A generalized additive regression model was used to analyze the relationship between outpatient visits for post-adolescent acne and short-term ambient AP exposure. The gender-specific analyses were conducted as well.

Results: Totally, 27,190 outpatient visits for post-adolescent acne were included. The results revealed that a $10 \mu \mathrm{g} / \mathrm{m}^{3}$ increase in $\mathrm{PM}_{10}, \mathrm{SO}_{2}$, and $\mathrm{NO}_{2}$ at lag $0-7$ day was associated with the increase of outpatient visits for post-adolescent acne at $0.84 \%$ (95\% CI: $0.53 \%, 1.16 \%$ ), $1.61 \%$ (95\% CI: $0.12 \%, 3.10 \%$ ), and $3.50 \%$ (95\% CI: $1.60 \%, 5.40 \%$ ), respectively. The significant positive associations of $\mathrm{PM}_{10}, \mathrm{SO}_{2}$, and $\mathrm{NO}_{2}$ were found at both single-lag models and moving average models. The gender-specific analyses showed that the effect estimates of $\mathrm{PM}_{10}$ was stronger for females than for males, while there was no observed gender difference in the effects of $\mathrm{SO}_{2}$ and $\mathrm{NO}_{2}$.

Conclusion: Short-term exposure to AP was associated with increased outpatient visits for post-adolescent acne, especially for females in the effects of $\mathrm{PM}_{10}$.

Keywords: short-term, air pollution, post-adolescent acne, adult acne, time-series analysis

\section{Introduction}

Acne vulgaris, an inflammatory disease of the pilosebaceous follicles, has been traditionally considered a common skin disease for teenagers. ${ }^{1}$ In recent years, the number of adults affected by new-onset acne or persistent acne is gradually rising.,3 Approximately $61.9 \%$ of populations in the United States ${ }^{4}$ and $41 \%$ of female individuals in France ${ }^{5}$ were found to be affected by acne during their adulthood. It results in with lower qualities of life and negative psychosocial conditions for patients. ${ }^{6,7}$

Especially, acne of adults over 25 years of age is generally defined as postadolescent acne, which is considered to be a particular subtype of acne differing from adolescent acne. ${ }^{8}$ It mainly occurs in females with mild-to-moderate severity. In addition, compared with adolescent acne, post-adolescent acne has more inflammatory lesions and less comedones. ${ }^{9}$ Moreover, unlike adolescent acne, which always appears on the forehead, nose, and upper cheeks, post-adolescent acne predominantly occurs on the chin, jawline, and neck. ${ }^{9}$ 
Many factors have been thought to be associated with the risk of acne, such as smoking habits, ${ }^{10}$ body mass index (BMI), ${ }^{11}$ genetic factors, ${ }^{12,13}$ and cosmetics, ${ }^{14}$ etc. Recent studies stressed that air pollution (AP) has adverse impacts on people's health, especially cardiovascular and pulmonary systems. ${ }^{15-22}$ Some studies also take AP's effects into consideration of the induction and aggravation of acne, because AP could contribute to hyper-seborrhea and hyper-sebum, both of which have been found to be prevalent in acne lesions. ${ }^{23-28}$ However, given that the clinical features of postadolescent acne, including the vulnerable population, the degree of inflammation, and the primary parts of bodies, were different from those of adolescent acne, the risk factors reported for acne are necessary to be reclassified and reidentified for both adults and teenagers. ${ }^{29}$ Attention should also be paid to the epidemiological evidence regarding the effect of AP on post-adolescent acne.

In this study, time-series analyses were conducted to investigate the association between outpatient visits for postadolescent acne and daily AP in Xi'an, a northwestern Chinese city with relatively heavy AP. Subgroup analyses were also carried out to investigate the potential gender difference in such association.

\section{Methods}

\section{Data for Outpatient Visits}

Daily outpatient visit data for post-adolescent acne between 1 October 2010 and 31 December 2013 were obtained from Xijing Hospital in Xi' an, a northwestern Chinese city with an area of $10,108 \mathrm{~km}^{2}$ and a population of over 8 million in 2014. ${ }^{30}$ It has distinct climate fluctuations with four seasons. The medical services of Xijing Hospital are accessible seven days a week. The diagnosis of acne vulgaris (ICD-10: L70) was defined by dermatologists according to Andrews' Diseases of the Skin-Clinical Dermatology (11th edition). Both new acne cases and the relapses of previous diagnosed patients whose residential areas were in Xi'an City and whose ages were over 25 years old were included. The informed consent of patients was not obtained because there was no individual interaction with patients. In addition, the Ethics Committee of Third Military Medical University (Army Military Medical University) approved this study, and the protocols complied with the Declaration of Helsinki.

\section{Environmental Data}

AP data between 1 October 2010 and 31 December 2013 were acquired from the Environmental Monitoring Center of Xi'an, including particulate matter less than $10 \mu \mathrm{m}$ in aerodynamic diameter $\left(\mathrm{PM}_{10}\right)$, sulfur dioxide $\left(\mathrm{SO}_{2}\right)$, and nitrogen dioxide $\left(\mathrm{NO}_{2}\right)$. The daily (24-h) mean concentrations were used as metrics of AP exposures, which were calculated by averaging hourly data across 13 monitoring stations covering Xi'an. The data of daily mean temperature and daily relative humidity during the study period were obtained from the local meteorological bureau.

\section{Statistical Analysis}

Firstly, the descriptive analyses were performed to characterize the basic information of outpatient visits, AP data, and meteorological data. The generalized additive model (GAM) was conducted to investigate the association between daily AP and outpatient visits for postadolescent acne because daily outpatient visits followed quasi-Poisson distribution. In such models, the outpatient visits of post-adolescent acne were included as the dependent variable, while daily AP, temperature, and relative humidity were included as independent variables. The formula used for the analyses and the choosing of degrees of freedom (df) were described in detail in our previous studies, ${ }^{31,32}$ and the formula was as follows:

$$
\begin{aligned}
\log \mathrm{E}\left(\mathrm{Y}_{\mathrm{t}}\right)=\beta \mathrm{Z}_{\mathrm{t}}+\mathrm{ns}(\text { temp }, 6)+\mathrm{ns}(\mathrm{RH}, 3) & +\mathrm{ns}(\text { time, } 7 / \text { year }) \\
& +\mathrm{DOW}_{\mathrm{t}}+\text { intercept }
\end{aligned}
$$

Gender-specific analyses were also conducted by Z-test. The estimated differences between gender subgroups were shown by the estimates of differences between groups and their $95 \%$ confidence intervals $(95 \%$ CIs).

Analyses were performed using the "mgcv" package in R 3.6.0 (http://www.r-project.org). The results were presented as the percentage increase of outpatient visits for post-adolescent acne with a $10 \mu \mathrm{g} / \mathrm{m}^{3}$ increase of $\mathrm{PM}_{10}$, $\mathrm{SO}_{2}$, and $\mathrm{NO}_{2}$ per day. $P$-values less than $0.05(P<0.05)$ were considered statistically significant.

\section{Results}

Table 1 shows demographic information of daily outpatient visits and environmental factors. Totally, 27,190 outpatient visits for post-adolescent acne were recorded, including 7,587 males and 19,603 females. The average daily outpatient visits were 22.9. During the period, the daily mean concentrations of $\mathrm{PM}_{10}, \mathrm{SO}_{2}, \mathrm{NO}_{2}$ were 142.6 $\mu \mathrm{g} / \mathrm{m}^{3}, 44.7 \mu \mathrm{g} / \mathrm{m}^{3}$, and $48.5 \mu \mathrm{g} / \mathrm{m}^{3}$, respectively. The average daily temperature was $14.3^{\circ} \mathrm{C}$ and relative humidity was $62.4 \%$. 
Table I Descriptive Statistics for Daily Outpatient Visits, Concentrations of Air Pollutants, and Weather Conditions

\begin{tabular}{|c|c|c|c|c|c|c|c|}
\hline & Mean & Min & Max & $\mathbf{P 2 5}$ & P50 & P75 & SD \\
\hline Post-adolescent acne & 22.9 & 0.0 & 60.0 & 17.0 & 22.0 & 28.0 & 9.1 \\
\hline \multicolumn{8}{|l|}{ Gender } \\
\hline Male & 6.4 & 0.0 & 20.0 & 4.0 & 6.0 & 8.0 & 3.4 \\
\hline Female & 16.5 & 0.0 & 49.0 & 11.0 & 16.0 & 21.0 & 7.2 \\
\hline \multicolumn{8}{|c|}{ Air pollutant concentrations (24-h average) } \\
\hline $\mathrm{PM}_{10}\left(\mu \mathrm{g} / \mathrm{m}^{3}\right)$ & 142.6 & 20.0 & 1020.0 & 86.0 & 122.0 & 166.0 & 96.2 \\
\hline $\mathrm{SO}_{2}\left(\mu \mathrm{g} / \mathrm{m}^{3}\right)$ & 44.7 & 8.0 & 202.0 & 20.0 & 30.0 & 60.8 & 34.9 \\
\hline $\mathrm{NO}_{2}\left(\mu \mathrm{g} / \mathrm{m}^{3}\right)$ & 48.5 & 14.4 & $|4| .0$ & 32.0 & 43.2 & 60.8 & 20.9 \\
\hline Mean Temperature $\left({ }^{\circ} \mathrm{C}\right)$ & 14.3 & -5.5 & 33.9 & 5.4 & 15.3 & 23.2 & 10.1 \\
\hline Mean Relative humidity (\%) & 62.4 & 16.0 & 98.0 & 51.0 & 63.0 & 74.8 & 16.8 \\
\hline
\end{tabular}

Notes: P25, P50, and P75: the 25th, 50th, and 75th percentiles.

Abbreviations: $\mathrm{PM}_{10}$, particulate matter with an aerodynamic diameter less than $10 \mu \mathrm{m} ; \mathrm{SO}_{2}$, sulfur dioxide; $\mathrm{NO}_{2}$, nitrogen dioxide; $\mathrm{SD}$, standard deviation.

In Figure 1, the time series of outpatient visits, air pollutants, and meteorological factors were shown. The outpatient visits for post-adolescent acne were increasing over time, especially those for female patients. AP was more severe during winter, and there were minor peaks of outpatient visits in the same period. The temperature had a significant undulation period over the year, which was higher during summers. However, the relative humidity showed no apparent seasonal trend.

In Figure 2, the correlations between AP and daily post-adolescent acne outpatient visits in single-lag days (lag 0 to lag 7) and cumulative exposure days (lag 0-1 to lag 0-7) were shown. In single-lag models, the positive association was evidenced from lag 0 to lag 3 and at lag 6 for $\mathrm{PM}_{10}$, at lag 3 for $\mathrm{SO}_{2}$, and from lag 0 to lag 3 for $\mathrm{NO}_{2}$. In cumulative exposure models, both $\mathrm{PM}_{10}$ and $\mathrm{NO}_{2}$ showed significant positive associations with outpatient visits for post-adolescent acne from lag0-1 to lag $0-7$, while $\mathrm{SO}_{2}$ had such associations from lag $0-4$ to lag 0 7. To be specific, every $10 \mu \mathrm{g} / \mathrm{m}^{3}$ increase of $\mathrm{PM}_{10}, \mathrm{SO}_{2}$, and $\mathrm{NO}_{2}$ was associated with the increase of outpatient acne visits at $0.84 \%$ (95\% CI: $0.53 \%, 1.16 \%), 1.61 \%$ (95\% CI: $0.12 \%, 3.10 \%)$, and $3.50 \%$ (95\% CI: $1.60 \%$, $5.40 \%$ ) at lag $0-7$ day, respectively. In gender-specific analyses, the significant association between $\mathrm{PM}_{10}$ and female outpatient visits for post-adolescent acne was observed from lag 0 to lag 6 and from $0-1$ to lag $0-7$, but no significant association was found for males, suggesting that females were more susceptible than males. The results of Z-test also showed that the association of $\mathrm{PM}_{10}$ was stronger in females than in males at lag 0-6 and lag 0-7 (Table S1). For $\mathrm{NO}_{2}$, the significant positive association was evidenced in both males and females. As for $\mathrm{SO}_{2}$, the significant positive association was only observed at lag 1 for males and at lag 0-7 for females. Thus, $\mathrm{PM}_{10}, \mathrm{SO}_{2}$ and $\mathrm{NO}_{2}$ concentrations were positively associated with the outpatient visits for post-adolescent acne, and the estimate effects of $\mathrm{PM}_{10}$ were stronger in females.

Figure 3 illustrates the exposure-response curves between air pollutants and outpatient-visits for postadolescent acne at lag 0-7 day. The relationships of both $\mathrm{PM}_{10}$ and $\mathrm{NO}_{2}$ were inverse $\mathrm{S}$-shaped in the curves. Specifically, the association of $\mathrm{PM}_{10}$ was linear when the concentrations were above $200 \mu \mathrm{g} / \mathrm{m}^{3}$ or below $100 \mu \mathrm{g} /$ $\mathrm{m}^{3}$, with no observed lower- and upper-bounds. Interestingly, the relationship turned to be flat when $\mathrm{PM}_{10}$ levels ranged from $100 \mu \mathrm{g} / \mathrm{m}^{3}$ to $200 \mu \mathrm{g} / \mathrm{m}^{3}$. For $\mathrm{NO}_{2}$, the linear relationship was observed when the concentrations were above $70 \mu \mathrm{g} / \mathrm{m}^{3}$ or below $40 \mu \mathrm{g} / \mathrm{m}^{3}$, with no observed lower- and upper-bounds. The relationship turned to be flatter when the its levels ranged from 40 $\mu \mathrm{g} / \mathrm{m}^{3}$ to $70 \mu \mathrm{g} / \mathrm{m}^{3}$. Compared with those of $\mathrm{PM}_{10}$ and $\mathrm{NO}_{2}$, the exposure-response curve of $\mathrm{SO}_{2}$ rose steadily in the entire range of pollutant concentrations, demonstrating its mild but still positive correlation with the risk of postadolescent acne.

Table 2 reveals the effects of two-pollutant models (lag 0-7). After adjusting for $\mathrm{PM}_{10}$ or $\mathrm{NO}_{2}$, the effect of $\mathrm{SO}_{2}$ turned to be statistically insignificant. Moreover, the effect of $\mathrm{NO}_{2}$ remained robust and statistically significant after adjusting for $\mathrm{SO}_{2}(3.75 \%, 95 \% \mathrm{CI}: 1.25 \%, 6.25 \%)$, but it turned to be insignificant after adjusting for $\mathrm{PM}_{10}(0.90 \%$, 95\% CI: $-1.38 \%, 3.19 \%)$. Furthermore, the effect of $\mathrm{PM}_{10}$ 

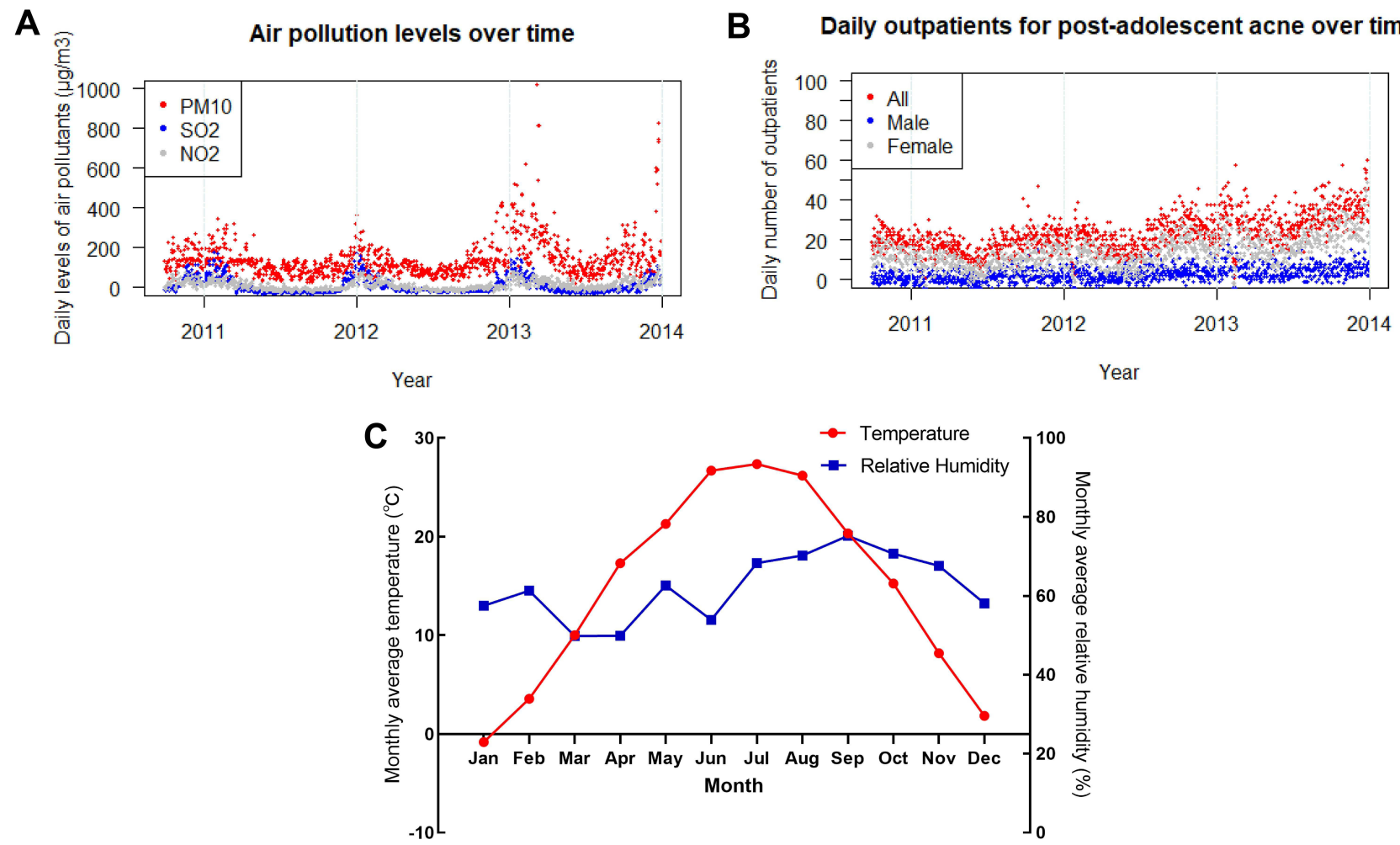

Figure I Original plots of outpatients, AP, and meteorological factors over time. (A and $\mathbf{B}$ ) shows the daily levels of $\mathrm{PM}_{10}, \mathrm{SO}_{2}$, and $\mathrm{NO}_{2}$, and the daily outpatient numbers for post-adolescent acne, respectively. (C) shows the monthly average temperature and relative humidity during the study period.

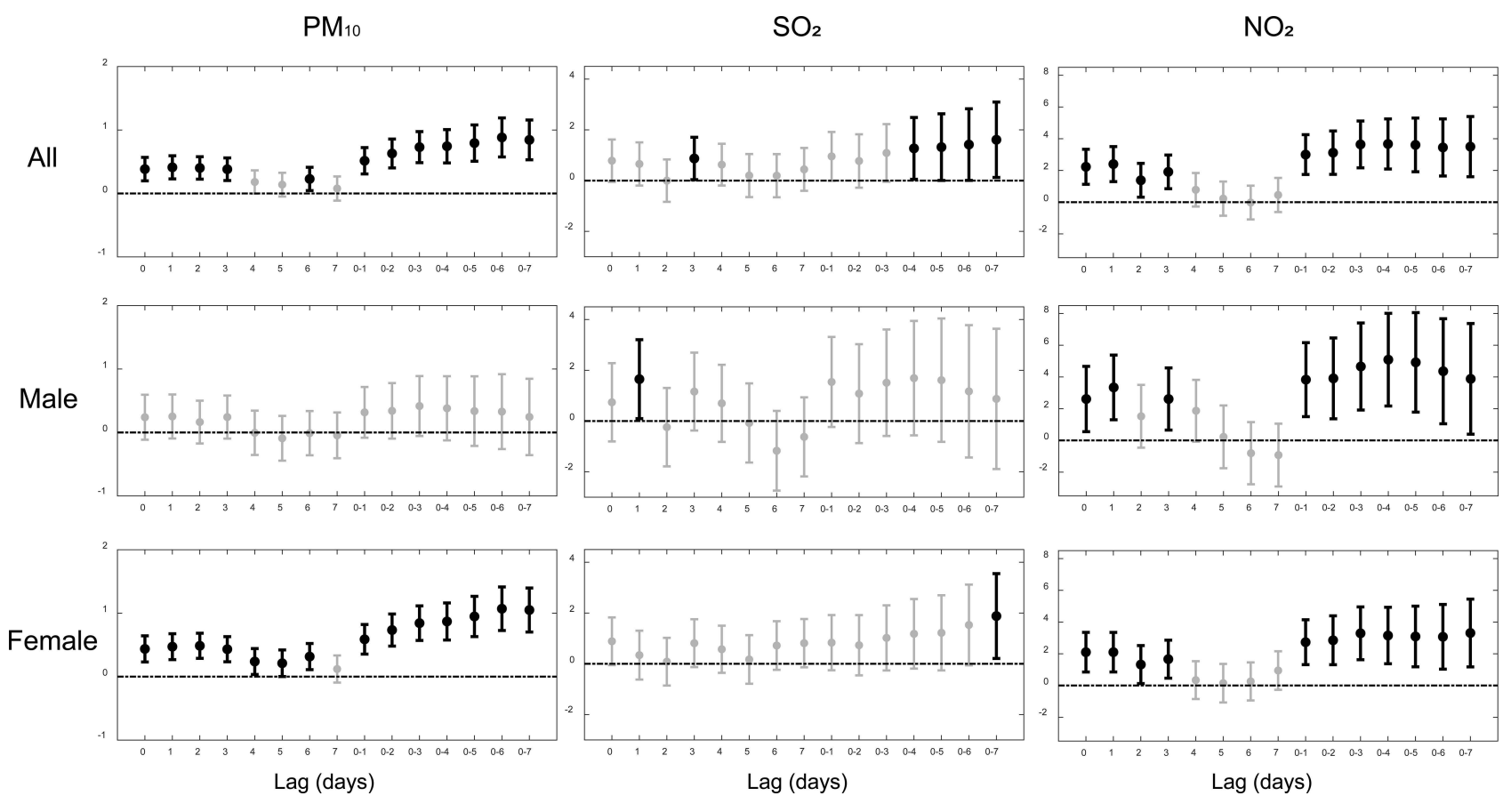

Figure 2 Percent change (mean and $95 \% \mathrm{Cl}$ ) of daily outpatient visits for post-adolescent acne associated with per $10 \mu \mathrm{g} / \mathrm{m}^{3}$ increase of pollutant concentrations at different lag days in different sex models. 

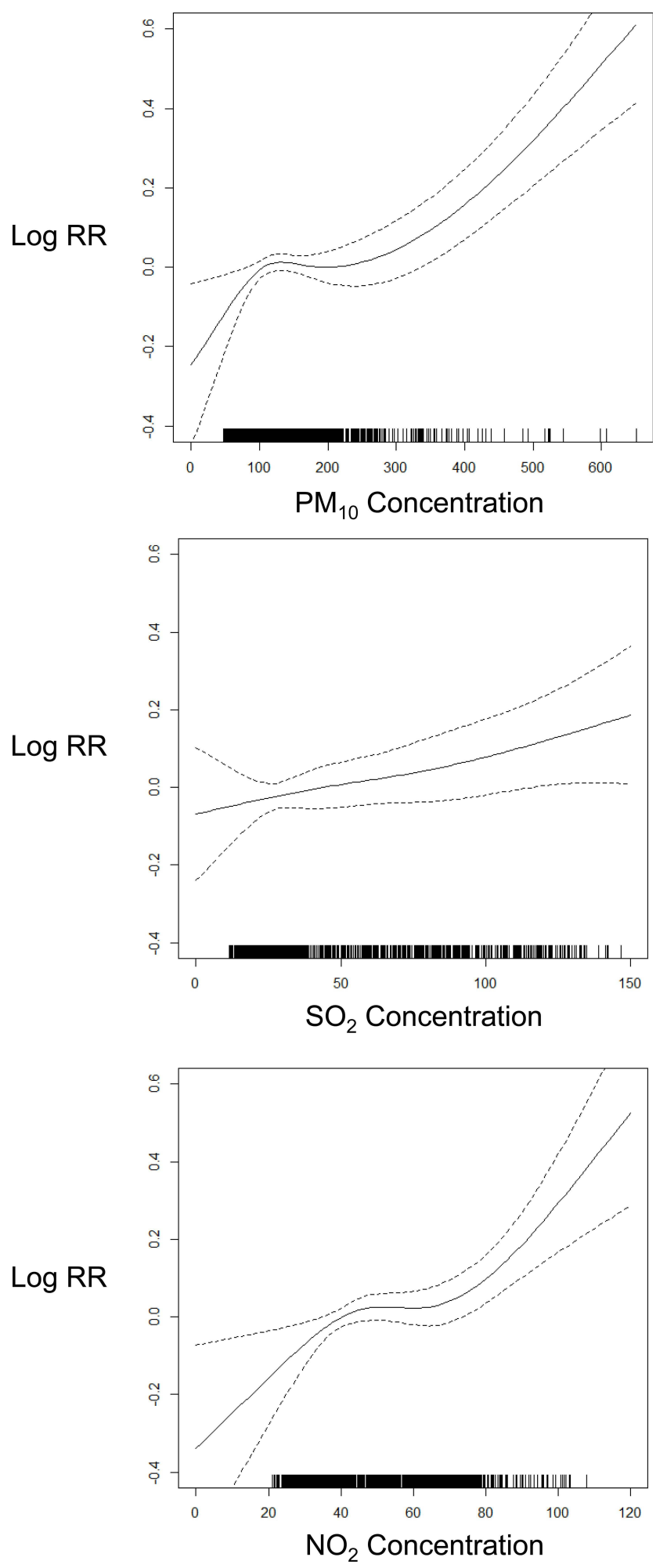

Figure 3 Exposure-response curves for air pollutants and post-adolescent acne. The $X$-axis is the pollutants' concentrations $\left(\mu \mathrm{g} / \mathrm{m}^{3}\right)$ at lag $0-7$ day. The $\mathrm{Y}$-axis is the log-relative risk of outpatient visits for post-adolescent acne with per $10 \mu \mathrm{g} / \mathrm{m}^{3}$ increase in pollutant concentration. The solid lines show the estimated mean percentages of change in daily outpatient visits for post-adolescent acne. The dotted lines represent the point-wise standard errors, which means $95 \%$ confidence intervals.
Table 2 Percent Change (Mean and 95\% Cl) of Daily Outpatient Visits for Post-Adolescent Acne Associated with per $10 \mu \mathrm{g} / \mathrm{m}^{3}$ Increase of Pollutant Concentration at Lag 0-7 Day in TwoPollutant Models

\begin{tabular}{|l|l|l|}
\hline & Two-Pollutant Models & Estimates \\
\hline $\mathrm{PM}_{10}$ & - & $0.84(0.53,1.16)^{*}$ \\
& $+\mathrm{SO}_{2}$ & $0.86(0.5 \mathrm{I}, \mathrm{I} .2 \mathrm{I}) *$ \\
& $+\mathrm{NO}_{2}$ & $0.76(0.38,1.14) *$ \\
\hline $\mathrm{SO}_{2}$ & - & $1.61(0.12,3.10) *$ \\
& $+\mathrm{PM}_{10}$ & $-0.18(-1.82,1.47)$ \\
& $+\mathrm{NO}_{2}$ & $-0.30(-2.26,1.65)$ \\
\hline $\mathrm{NO}_{2}$ & - & $3.50(1.60,5.40) *$ \\
& $+\mathrm{PM}_{10}$ & $0.90(-1.38,3.19)$ \\
& $+\mathrm{SO}_{2}$ & $3.75(1.25,6.25) *$ \\
\hline
\end{tabular}

Note: $* P<0.05$.

Abbreviations: $\mathrm{PM}_{10}$, particulate matter with an aerodynamic diameter less than $10 \mu \mathrm{m} ; \mathrm{SO}_{2}$, sulfur dioxide; $\mathrm{NO}_{2}$, nitrogen dioxide.

increased slightly after adjusting for $\mathrm{SO}_{2}(0.86 \%, 95 \% \mathrm{CI}$ : $0.51 \%, 1.21 \%$ ), while its effect mildly decreased but still obvious after adjusting for $\mathrm{NO}_{2}(0.76 \%, 95 \%$ CI: $0.38 \%, 1.14 \%)$.

\section{Discussion}

In this study, we provided novel evidence of the relationship between short-term AP exposure and outpatient visits for post-adolescent acne. Through time-series analyses, we found positive associations between outpatient visits for post-adolescent acne and short-term exposure to ambient $\mathrm{PM}_{10}, \mathrm{SO}_{2}$, and $\mathrm{NO}_{2}$. In gender subgroup analyses, the associations of $\mathrm{PM}_{10}$ appeared to be more significant in females than in males.

Although acne is typically recognized as an adolescent disorder, a series of studies have reported that the incidence of acne in adults over 25 years old has steadily grown over time. ${ }^{2,33,34} \mathrm{~A}$ consistent rise in the outpatient visits for post-adolescent acne also has been found in Xi'an, China during the study period. The reason for such growth was complex and might be attributed to that some lifestyle factors associated with post-adolescent acne such as smoking ${ }^{35}$ and western $\operatorname{diet}^{36,37}$ are gradually prevalent in adults. ${ }^{38,39}$ However, the outpatient visits for post-adolescent acne exhibited a season variation, peaking in winter and decreasing in summer. Such variation indicated that some factors vary with seasonal fluctuation, such as environmental factors, may also affect the 
incidence and the aggravation of post-adolescent acne. Especially, in the present study, the levels of air pollutants $\left(\mathrm{PM}_{10}, \mathrm{SO}_{2}, \mathrm{NO}_{2}\right)$ also showed season variations, which seem to have the same fluctuations with the outpatient visits for post-adolescent acne. Therefore, it's imperative to investigate the association between post-adolescent acne and ambient AP.

Our study observed an obvious relationship between short-term exposures to $\mathrm{PM}_{10}, \mathrm{SO}_{2}$, and $\mathrm{NO}_{2}$ and outpatient visits for post-adolescent acne, which was consistent with previous studies investigating the associations between AP and some inflammatory skin diseases. For example, Guo et $\mathrm{al}^{40}$ suggested that short-term exposure to AP, represented by PM, was significantly related to the outpatient visits for eczema and dermatitis. Li et $\mathrm{al}^{41}$ found that shortterm elevations of $\mathrm{PM}_{10}, \mathrm{SO}_{2}$, and $\mathrm{NO}_{2}$ were associated with the increased outpatient visits for eczema. Moreover, Kim et $\mathrm{al}^{42}$ also indicated that the risk of atopic dermatitis symptoms in young children could be increased with shortterm exposure to $\mathrm{PM}_{10}, \mathrm{NO}_{2}$, and ozone $\left(\mathrm{O}_{3}\right)$. Such correlations were plausible from a biological perspective: skin, a barrier between internal and external environment, directly contacts air pollutants. Various airborne pollutants can permeate the epidermal barrier, and then trigger skin barrier dysfunction, ${ }^{43}$ immune dysregulation, ${ }^{44}$ and dermal inflammation. ${ }^{45}$ In such processes, the induction of inflammatory cascade, generation of free radicals, activation of AhR (aryl hydrocarbon receptor), and alterations of cutaneous microflora resulted from air pollutants all may be involved in the inflammatory processes and immune responses of post-adolescent acne. ${ }^{46,47}$

Furthermore, our data showed that the association between post-adolescent acne outpatient visits and $\mathrm{PM}_{10}$ was more evident in females than in males. One possible explanation was that exposure to PM could result in the imbalance of female hormones via interfering with estrogen-regulated pathways. ${ }^{48,49}$ Given that the severity of female acne could fluctuate with hormones in their lifespan, especially in the period of menstruation, pregnancy, and menopause, the irregular changes of hormones affected by AP, especially PM, may further enhance the possibility of the onset and aggravation of post-adolescent acne during female adulthood. ${ }^{3,50}$ This can also, at least partly, explain why post-adolescent acne is more prevalent in females than in males. ${ }^{34,51}$ In another perspective, males and females have physiological, chemical, and biophysical differences in skin. ${ }^{52}$ Such gender difference of skin characteristics in terms of stratum corneum hydration, transepidermal water loss, sebum production, and skin thickness may contribute to their dissimilar abilities against environmental stressors, including AP. From this viewpoint, this study indicated that male skin seems to have stronger properties to counteract or prevent against AP-induced skin damages.

Although it is unavoidable for skin to exposure to air pollutants, many anti-pollutant strategies can be taken into consideration to decrease the risk of post-adolescent acne. To begin with, moisturizer can be utilized to accelerate the recovery of skin barrier and prevent contaminants from adhering directly to the skin. ${ }^{53}$ Furthermore, oral or topical antioxidants such as vitamin $\mathrm{E}^{54}$ and anti-inflammatory drugs such as adapalene and benzoyl peroxide can be conducive to relieve pollution-induced skin oxidation and inflammation. ${ }^{55}$ Lastly, governments should make specific policies to control AP and to reduce the exposure levels of air pollutants. $^{56-59}$

This study has several major advantages. Firstly, this study was conducted with a large sample of postadolescent acne outpatients. Secondly, we provided the first evidence that short-term exposure to AP may contribute to the increased risk of post-adolescent acne. Thirdly, this research was conducted in Xi'an, a major metropolis in northwestern China with a considerably large population and relatively heavy pollution.

Nonetheless, this study has several limitations. Firstly, like other similar ecological studies, air pollutant levels from fixed site monitoring stations instead of individual exposure levels were included into the main analysis models, which can lead to exposure errors known as "ecological fallacy". Secondly, the data of other pollutants were not available, including particulate matter less than $2.5 \mu \mathrm{m}$ in aerodynamic diameter $\left(\mathrm{PM}_{2.5}\right), \mathrm{O}_{3}$, and carbon monoxide (CO). Thirdly, also owing to the limitation of the availability, more confounders which may have potential effects on the relationship between AP and post-adolescent acne were not included for analyses, such as stress status, body mass index, and drug history. ${ }^{60,61}$ Fourthly, our data were only collected from a single hospital, which may make our results less representative of the whole city. Therefore, more work is needed to confirm our results in the future.

\section{Conclusions}

In conclusion, short-term air pollution $\left(\mathrm{PM}_{10}, \mathrm{SO}_{2}\right.$, and $\left.\mathrm{NO}_{2}\right)$ exposure was associated with the increased risk of outpatient visits for post-adolescent acne. More interestingly, females were more sensitive to $\mathrm{PM}_{10}$ than men. This study provided 
novel evidence regarding the relationship between short-term ambient AP exposure and post-adolescence acne, which may have an important bearing on the intervention and prevention of this disease.

\section{Abbreviation}

AP, air pollution; $\mathrm{CO}$, carbon monoxide; DOW, day of the week; df, degree of freedom; GAM, generalized additive model; $\mathrm{NO}_{2}$, nitrogen dioxide; $\mathrm{O}_{3}$, ozone; $\mathrm{PACF}$, partial autocorrelation function; $\mathrm{PM}_{10}$, particulate matter less than $10 \mu \mathrm{m}$ in aerodynamic diameter; $\mathrm{PM}_{2.5}$, particulate matter less than $2.5 \mu \mathrm{m}$ in aerodynamic diameter; $\mathrm{SO}_{2}$, sulfur dioxide.

\section{Acknowledgments}

We would like to acknowledge the financial supports from the Outstanding Talent Support Program of Army Medical University, Innovative Training Program Foundation for the Talents of the Daping Hospital [2019CXJSC034], and Research and innovation projects of graduate students in Chongqing [CYS20367].

\section{Disclosure}

No potential conflict of interest was reported by the authors.

\section{References}

1. Tan JK, Bhate K. A global perspective on the epidemiology of acne. Br J Dermatol. 2015;172(Suppl 1):3-12. doi:10.1111/bjd.13462

2. Shen Y, Wang T, Zhou C, et al. Prevalence of acne vulgaris in Chinese adolescents and adults: a community-based study of 17,345 subjects in six cities. Acta Derm Venereol. 2012;92(1):40-44. doi:10.2340/ 00015555-1164

3. Perkins AC, Maglione J, Hillebrand GG, Miyamoto K, Kimball AB. Acne vulgaris in women: prevalence across the life span. $J$ Womens Health. 2012;21(2):223-230. doi:10.1089/jwh.2010.2722

4. Yentzer BA, Hick J, Reese EL, Uhas A, Feldman SR, Balkrishnan R. Acne vulgaris in the United States: a descriptive epidemiology. Cutis. 2010;86(2):94-99.

5. Poli F, Dreno B, Verschoore M. An epidemiological study of acne in female adults: results of a survey conducted in France. $J$ Eur Acad Dermatol Venereol. 2001;15(6):541-545. doi:10.1046/j.14683083.2001.00357.x

6. Zeichner JA, Baldwin HE, Cook-Bolden FE, Eichenfield LF, FallonFriedlander S, Rodriguez DA. Emerging issues in adult female acne. J Clin Aesthet Dermatol. 2017;10(1):37-46.

7. Chilicka K, Maj J, Panaszek B. General quality of life of patients with acne vulgaris before and after performing selected cosmetological treatments. Patient Prefer Adherence. 2017;11:1357-1361. doi:10.2147/PPA.S131184

8. Williams C, Layton AM. Persistent acne in women: implications for the patient and for therapy. Am J Clin Dermatol. 2006;7(5):281-290. doi:10.2165/00128071-200607050-00002

9. Holzmann R, Shakery K. Postadolescent acne in females. Skin Pharmacol Physiol. 2014;27(Suppl 1):3-8. doi:10.1159/000354887
10. Capitanio B, Sinagra JL, Ottaviani M, Bordignon V, Amantea A, Picardo M. Acne and smoking. Dermato-Endocrinology. 2009;1 (3):129-135. doi:10.4161/derm.1.3.9638

11. Lu PH, Hsu CH. Body mass index is negatively associated with acne lesion counts in Taiwanese women with post-adolescent acne. $J$ Eur Acad Dermatol Venereol. 2015;29(10):2046-2050. doi:10.1111/ jdv. 12754

12. Yang T, Wu WJ, Tian LM, et al. The associations of androgen-related genes CYP21A2 and CYP19A1 with severe acne vulgaris in patients from Southwest China. Clin Cosmet Investig Dermatol. 2021;14:313-331. doi:10.2147/CCID.S293171

13. Tian LM, Ke D. Acne vulgaris is associated with the human beta-defensin 1-gene polymorphisms in Han Chinese ethnic group patients. Clin Cosmet Investig Dermatol. 2021;14:123-128. doi:10.2147/CCID.S292797

14. Monfrecola G, Cacciapuoti S, Capasso C, Delfino M, Fabbrocini G. Tolerability and camouflaging effect of corrective makeup for acne: results of a clinical study of a novel face compact cream. Clin Cosmet Investig Dermatol. 2016;9:307-313. doi:10.2147/CCID.S115192

15. Shahi AM, Omraninava A, Goli M, Soheilarezoomand HR, Mirzaei N. The effects of air pollution on cardiovascular and respiratory causes of emergency admission. Emergency. 2014;2(3):107-114.

16. Burgess JL, Fleming JE, Mulenga EM, et al. Acute changes in sputum IL-10 following underground exposure to diesel exhaust. Clin Toxicol. 2007;45(3):255-260. doi:10.1080/15563650601072142

17. Zhou Z, Shao T, Qin M, et al. The effects of autophagy on vascular endothelial cells induced by airborne PM2.5. J Environ Sci. 2018;66:182-187. doi:10.1016/j.jes.2017.05.019

18. Xiao H, Zhang H. Skin inflammation and psoriasis may be linked to exposure of ultrafine carbon particles. $J$ Environ Sci. 2020;96:206-208. doi:10.1016/j.jes.2020.06.028

19. Chi R, Li H, Wang Q, et al. Association of emergency room visits for respiratory diseases with sources of ambient PM2.5. J Environ Sci. 2019;86:154-163. doi:10.1016/j.jes.2019.05.015

20. Cheng Z, Liang X, Liang S, Yin N, Faiola F. A human embryonic stem cell-based in vitro model revealed that ultrafine carbon particles may cause skin inflammation and psoriasis. $J$ Environ Sci. 2020;87:194-204. doi:10.1016/j.jes.2019.06.016

21. Sun H, Chen H, Yao L, et al. Sources and health risks of PM2.5-bound polychlorinated biphenyls (PCBs) and organochlorine pesticides (OCPs) in a North China rural area. $J$ Environ Sci. 2020;95:240-247. doi:10.1016/j.jes.2020.03.051

22. Wang D, Li X, Zhang X, et al. Spatial distribution of health risks for residents located close to solvent-consuming industrial VOC emission sources. $J$ Environ Sci. 2021;107:38-48. doi:10.1016/j. jes.2021.01.014

23. Kim KE, Cho D, Park HJ. Air pollution and skin diseases: adverse effects of airborne particulate matter on various skin diseases. Life Sci. 2016;152:126-134. doi:10.1016/j.1fs.2016.03.039

24. Liu W, Pan X, Vierkotter A, et al. A time-series study of the effect of air pollution on outpatient visits for acne vulgaris in Beijing. Skin Pharmacol Physiol. 2018;31(2):107-113. doi:10.1159/000484482

25. Lefebvre MA, Pham DM, Boussouira B, Bernard D, Camus C, Nguyen QL. Evaluation of the impact of urban pollution on the quality of skin: a multicentre study in Mexico. Int J Cosmet Sci. 2015;37(3):329-338. doi:10.1111/ics.12203

26. Lefebvre MA, Pham DM, Boussouira B, et al. Consequences of urban pollution upon skin status. A controlled study in Shanghai area. Int J Cosmet Sci. 2016;38(3):217-223. doi:10.1111/ics. 12270

27. Nouveau-Richard S, Zhu W, Li YH, et al. Oily skin: specific features in Chinese women. Skin Res Technol. 2007;13(1):43-48. doi:10.1111/ j.1600-0846.2006.00185.x

28. Abolhasani R, Araghi F, Tabary M, Aryannejad A, Mashinchi B, Robati RM. The impact of air pollution on skin and related disorders: a comprehensive review. Dermatol Ther. 2021;34(2):e14840. doi:10.1111/dth.14840 
29. Khunger N, Kumar C. A clinico-epidemiological study of adult acne: is it different from adolescent acne? Indian J Dermatol Venereol Leprol. 2012;78(3):335-341. doi:10.4103/0378-6323.95450

30. Yang Y, Jia Y, Ling S, Yao C. Urban natural resource accounting based on the system of environmental economic accounting in Northwest China: a case study of Xi'an. Ecosyst Serv. 2021;47:101233. doi:10.1016/j.ecoser.2020.101233

31. Liang Z, Xu C, Fan Y-N, et al. Association between air pollution and menstrual disorder outpatient visits: a time-series analysis. Ecotoxicol Environ Saf. 2020;192:110283. doi:10.1016/j.ecoenv.2020.110283

32. Xu C, Fan YN, Liang Z, et al. Unexpected association between increased levels of ambient carbon monoxide and reduced daily outpatient visits for vaginitis: a hospital-based study. Sci Total Environ. 2020;723:137923. doi:10.1016/j.scitotenv.2020.137923

33. Skroza N, Tolino E, Mambrin A, et al. Adult acne versus adolescent acne: a Retrospective Study of 1167 patients. J Clin Aesthet Dermatol. 2018;11(1):21-25.

34. Han XD, Oon HH, Goh CL. Epidemiology of post-adolescence acne and adolescence acne in Singapore: a 10-year retrospective and comparative study. J Eur Acad Dermatol Venereol. 2016;30 (10):1790-1793. doi:10.1111/jdv.13743

35. Yang YS, Lim HK, Hong KK, et al. Cigarette smoke-induced interleukin-1 alpha may be involved in the pathogenesis of adult acne. Ann Dermatol. 2014;26(1):11-16. doi:10.5021/ad.2014.26.1.11

36. Romanska-Gocka K, Wozniak M, Kaczmarek-Skamira E, Zegarska B. The possible role of diet in the pathogenesis of adult female acne. Postepy Dermatol Alergol. 2016;33(6):416-420. doi:10.5114/ada.2016.63880

37. Alhetheli G, Elneam AIA, Alsenaid A, Al-Dhubaibi M. Vitamin $\mathrm{D}$ levels in patients with and without acne and its relation to acne severity: a Case-Control Study. Clin Cosmet Investig Dermatol. 2020;13:759-765. doi:10.2147/CCID.S271500

38. Mendez D, Tam J, Giovino GA, Tsodikov A, Warner KE. Has smoking cessation increased? An examination of the US adult smoking cessation rate 1990-2014. Nicotine Tob Res. 2017;19 (12):1418-1424. doi:10.1093/ntr/ntw239

39. Cordain L, Eaton SB, Sebastian A, et al. Origins and evolution of the Western diet: health implications for the 21st century. Am J Clin Nutr. 2005;81(2):341-354. doi:10.1093/ajen.81.2.341

40. Guo Q, Liang F, Tian L, Schikowski T, Liu W, Pan X. Ambient air pollution and the hospital outpatient visits for eczema and dermatitis in Beijing: a time-stratified case-crossover analysis. Environ Sci Process Impacts. 2019;21(1):163-173. doi:10.1039/c8em00494c

41. Li Q, Yang Y, Chen R, et al. Ambient air pollution, meteorological factors and outpatient visits for eczema in Shanghai, China: a time-series analysis. Int $J$ Environ Res Public Health. 2016;13 (11):1106. doi:10.3390/ijerph13111106

42. Kim YM, Kim J, Han Y, Jeon BH, Cheong HK, Ahn K. Short-term effects of weather and air pollution on atopic dermatitis symptoms in children: a panel study in Korea. PLoS One. 2017;12(4):e0175229. doi:10.1371/journal.pone.0175229

43. Karki P, Meliton A, Shah A, et al. Role of truncated oxidized phospholipids in acute endothelial barrier dysfunction caused by particulate matter. PLoS One. 2018;13(11):e0206251. doi:10.1371/ journal.pone.0206251

44. Zhu TH, Zhu TR, Tran KA, Sivamani RK, Shi VY. Epithelial barrier dysfunctions in atopic dermatitis: a skin-gut-lung model linking microbiome alteration and immune dysregulation. $\mathrm{Br} J$ Dermatol. 2018;179(3):570-581. doi:10.1111/bjd.16734
45. Verdin A, Cazier F, Fitoussi R, et al. An in vitro model to evaluate the impact of environmental fine particles (PM0.3-2.5) on skin damage. Toxicol Lett. 2019;305:94-102. doi:10.1016/j.toxlet.2019.01.016

46. Mancebo SE, Wang SQ. Recognizing the impact of ambient air pollution on skin health. J Eur Acad Dermatol Venereol. 2015;29 (12):2326-2332. doi:10.1111/jdv.13250

47. Jusuf NK, Putra IB, Sari L. Differences of microbiomes found in non-inflammatory and inflammatory lesions of acne vulgaris. Clin Cosmet Investig Dermatol. 2020;13:773-780. doi:10.2147/CCID. $\mathrm{S} 272334$

48. Wenger D, Gerecke AC, Heeb NV, et al. In vitro estrogenicity of ambient particulate matter: contribution of hydroxylated polycyclic aromatic hydrocarbons. J Appl Toxicol. 2009;29(3):223-232. doi: $10.1002 /$ jat. 1400

49. Clougherty JE. A growing role for gender analysis in air pollution epidemiology. Environ Health Perspect. 2010;118(2):167-176. doi:10.1289/ehp.0900994

50. Khunger N, Mehrotra K. Menopausal acne - challenges and solutions. Int J Womens Health. 2019;11:555-567. doi:10.2147/IJWH.S174292

51. Dreno B, Thiboutot D, Layton AM, et al. Large-scale international study enhances understanding of an emerging acne population: adult females. J Eur Acad Dermatol Venereol. 2015;29(6):1096-1106. doi:10.1111/jdv.12757

52. Rahrovan S, Fanian F, Mehryan P, Humbert P, Firooz A. Male versus female skin: what dermatologists and cosmeticians should know. Int $J$ Womens Dermatol. 2018;4(3):122-130. doi:10.1016/j. ijwd.2018.03.002

53. Lebwohl M, Herrmann LG. Impaired skin barrier function in dermatologic disease and repair with moisturization. Cutis. 2005;76(6 Suppl):7-12.

54. Chan H, Chan G, Santos J, Dee K, Co JK. A randomized, double-blind, placebo-controlled trial to determine the efficacy and safety of lactoferrin with vitamin $\mathrm{E}$ and zinc as an oral therapy for mild to moderate acne vulgaris. Int J Dermatol. 2017;56(6):686-690. doi:10.1111/ijd.13607

55. Kircik LH. Anti-inflammatory dose doxycycline plus adapalene $0.3 \%$ and benzoyl peroxide $2.5 \%$ gel for severe acne. J Drugs Dermatol. 2019;18(9):924-927.

56. Wang Q, Fang J, Shi W, Dong X. Distribution characteristics and policy-related improvements of PM2.5 and its components in six Chinese cities. Environ Pollut. 2020;266(Pt3):115299. doi:10.1016/ j.envpol.2020.115299

57. Huang X, Tang G, Zhang J, et al. Characteristics of PM2.5 pollution in Beijing after the improvement of air quality. $J$ Environ Sci. 2021;100:1-10. doi:10.1016/j.jes.2020.06.004

58. Wang S, Xing J, Zhao B, Jang C, Hao J. Effectiveness of national air pollution control policies on the air quality in metropolitan areas of China. J Environ Sci. 2014;26(1):13-22. doi:10.1016/s1001-0742(13) 60381-2

59. Bai H, Gao W, Zhang Y, Wang L. Assessment of health benefit of PM2.5 reduction during COVID-19 lockdown in China and separating contributions from anthropogenic emissions and meteorology. J Environ Sci. 2021. doi:10.1016/j.jes.2021.01.022

60. Goodman G. Acne-natural history, facts and myths. Aust Fam Physician. 2006;35(8):613-616.

61. Jusuf NK, Putra IB, Sutrisno AR. Correlation between stress scale and serum substance $\mathrm{P}$ level in acne vulgaris. Int J Gen Med. 2021;14:681-686. doi:10.2147/IJGM.S294509 


\section{Publish your work in this journal}

Clinical, Cosmetic and Investigational Dermatology is an international, peer-reviewed, open access, online journal that focuses on the latest clinical and experimental research in all aspects of skin disease and cosmetic interventions. This journal is indexed on CAS
The manuscript management system is completely online and includes a very quick and fair peer-review system, which is all easy to use. Visit http://www.dovepress.com/testimonials.php to read real quotes from published authors.

Submit your manuscript here: https://www.dovepress.com/clinical-cosmetic-and-investigational-dermatology-journal 